\title{
5
}

\section{Antenatal Screening and HIV-Pregnancy: Strategies for Treatment}

\author{
Ali A. Al-Jabri', Abdullah A. Balkhair², \\ Mohammed S. Al-Balosh ${ }^{3}$ and Sidgi S. Hasson ${ }^{3}$ \\ ${ }^{1}$ Head of Immunology Division, Department of Microbiology and Immunology, \\ College of Medicine and Health Sciences, Sultan Qaboos University, Muscat, \\ ${ }^{2}$ Head of Infectious Diseases Unit, Department of Medicine, \\ Sultan Qaboos University Hospital,Muscat, \\ ${ }^{3}$ Department of Microbiology and Immunology, College of Medicine and Health Sciences, \\ Sultan Qaboos University, Muscat,
}

Oman

\section{Introduction}

More than half of all people living with HIV are women and girls (WHO \& UNAIDS, 2010). In sub-Saharan Africa, more women than men are living with HIV, and young women aged 15-24 years are as much as eight times more likely than men to be HIV positive (WHO \& UNAIDS, 2010). In developed countries, the women who are intravenous drug users, partners of drug users or bisexual men, or involved in sex work are more likely to be positive for HIV (WHO \& UNAIDS, 1999). There are higher proportions of young women than young men who acquired HIV infection through sex. Their exposure to the virus at an earlier age, coupled with physiological and sociological factors increases their risk (WHO \& UNAIDS, 1999).

Globally, HIV is the leading cause of death in women of reproductive age. Since nearly all HIV infections in children are acquired from their mothers, the global epidemiology of HIV in children reflects that of HIV in women. Nearly all such infections can be prevented by programs providing highly effective antiretroviral therapy (ART) and antiretroviral (ARV) prophylaxis interventions.

There are tremendous efforts to control HIV/AIDS and reduce the mortality and morbidity rates by improving the accessibility to ART to all HIV- infected patients, trying to eradicate the virus from reservoirs of infection and designing an effective vaccine that can elicit protective antibody response as well as cell mediated response against HIV (Al-Jabri \& AlEnzi, 2009). An important step in the fight against HIV/AIDS is to perform antenatal screening and counseling.

\section{The importance of antenatal screening and counseling}

HIV testing of individuals should be undertaken only when they are informed about the test and should be entirely voluntary. HIV testing and counseling enable women to learn whether they are infected, understand their HIV status and make more informed choices for 
the future. HIV testing and counseling also provide essential knowledge and support: they enable uninfected women to remain so, enable those infected with HIV to plan for the future and prevent HIV transmission to others. Those who are infected can also benefit from available care, treatment and support services. Knowledge of HIV infection leads to initiate ART for the long-term treatment of women living with HIV and intervenes with the transmission of HIV infections to infants and young children.

HIV testing in pregnancy is important for many reasons, but this must be balanced against the possible risks of stigmatization, discrimination and violence. Voluntary counseling and testing should be encouraged for pregnant women and couples. Post-test counseling is extremely important following a diagnosis of HIV and should include information about pregnancy-related issues and the risk of mother to child transmission (MTCT). Counseling is also important for HIV-negative women as it provides an opportunity for risk-reduction.

HIV-infected women who know their sero-status are able to make informed choices about their reproductive lives and, if pregnant, to access specific interventions, such as ARV drugs and infant-feeding counseling and support, which can significantly reduce the risk of MTCT of HIV. Currently, the majority of people infected with HIV unaware of their status and cannot receive the services they actually need.

A key factor limiting the scale-up of MTCT programs is lack of knowledge of HIV status (AlJabri et al. 2010). Increasing the availability and acceptability of HIV testing and counseling services, with no dough, will encourage more women to know their status, providing a gateway to MTCT interventions (Bolu et al. 2007). Key factors contributing to the scale-up of testing and counseling include a policy of provider-initiated testing and counseling with the right to refuse testing; group pretest counseling; rapid HIV testing; innovative staffing strategies; and community and male involvement. Integration of testing and counseling within the community and all maternal and child health settings are critical for scaling-up and for linking women and their families to care and treatment services (Bolu et al. 2007).

\section{Strategies for treatment}

Three types of interventions should be tackled by any program concerned with prevention of MTCT: primary prevention of HIV in women; prophylaxis with ARV drugs in breastfeeding infants and prophylaxis with ARV drugs for lactating mothers.

Taking ARV treatment can reduce the risk of MTCT. There are two different ways in which drugs can act. First, they may reduce the viral load so the baby is exposed to less of the virus while in the uterine and during childbirth. The aim of HIV treatment is to decrease the viral load $<50$ copies $/ \mathrm{ml}$. Second, the drugs may cross the placenta and enter the baby's body, where they can prevent the virus from ever taking hold.

One of the key attainments in HIV research was the demonstration by the Pediatric AIDS Clinical Trials Group 076 (PACTG 076) that administration of zidovudine to the pregnant woman and her infant could reduce the risk of perinatal transmission (PT) by nearly $70 \%$ (Connor et al. 1994). Following the results of PACTG 076, implementation of the zidovudine regimen coupled with increased antenatal HIV testing and counseling rapidly resulted in significant declines in HIV transmission (CDC, 2006). Subsequent clinical trials and observational studies showed that combination ARV prophylaxis (initially dual and then triple combination therapy) given to the mother antenatally was associated with further declines in transmission to less than $2 \%$ (Cooper et al. 2002, WHO 2010). 


\section{Mechanisms of action of ARV prophylaxis in reducing perinatal transmission of HIV}

There are a number of mechanisms through which zidovudine or other ARV drugs can reduce PT. One central mechanism is by decreasing maternal viral load in the blood and genital secretions via antenatal drug administration, particularly in women with high viral loads. However, ARV drugs have been shown to reduce the risk of transmission even among women with HIV RNA levels $<1,000$ copies/ml (Ioannidis et al. 2001). Additionally, the level of HIV RNA at delivery and receipt of antenatal ART are each independently associated with the risk of transmission, suggesting that ARV prophylaxis does not work solely through reduction in viral load (Sperling et al. 1996).

An additional mechanism of protection is pre-exposure infant prophylaxis provided by administration of ARV drugs that cross the placenta from the mother to the infant, resulting in adequate systemic drug levels in the infant. This mechanism of protection is particularly significant during the infant's passage through the birth canal, a time of rigorous exposure to maternal genital tract virus. Post-exposure infant prophylaxis is provided through administration of drug to the infant after birth. This mechanism protects the infant from cellfree or cell-associated virus that might have obtained access to the fetal/infant systemic circulation. This can occur through maternal-fetal transfusion during uterine contractions in labor or through systemic dissemination of virus swallowed by the infant during passage through the birth canal.

It is predictable that efficacy of ARV drugs in reducing PT is multi-factorial, and each of these mechanisms is contributory. The efficacy of ARV regimens administered only during labor and/or to the newborn in reducing PT demonstrates the importance of the pre- and post-exposure components of prophylaxis in reducing PT (Wade et al. 1998).

\section{Perinatal transmission of HIV and maternal viral load}

In PACTG 076, antenatal maternal HIV RNA copy number was associated with HIV transmission in women receiving placebo. In women receiving zidovudine, the relationship was markedly attenuated and no longer statistically significant (Sperling et al. 1996). An HIV RNA threshold below which there was no risk of transmission was not identified; zidovudine was effective in reducing transmission regardless of maternal HIV RNA copy number (Shapiro et al. 1999). Other data from larger numbers of zidovudine-treated, HIVinfected pregnant women indicate that HIV RNA levels correlate with risk of transmission even in women treated with ARV agents (The European Collaborative Study, 1999).

Although the risk of PT in women with undetectable HIV RNA levels appears to be extremely low, transmission from mother to infant has been reported among women with all levels of maternal HIV RNA. Additionally, although HIV RNA may be an important risk factor for transmission, other factors also appear to play a role (Mock et al. 1999). Although there is a general correlation between viral load in plasma and in the genital tract, discordance has also been reported, particularly between HIV proviral load in blood and genital secretions, especially in the presence of other genital tract infections (Hart et al. 1999).

The use of ARV drugs during pregnancy for prevention of PT should be discussed with and offered to all infected pregnant women regardless of their HIV RNA level. Results of epidemiologic and clinical trials suggest that women receiving potent combinations of ARV 
drugs that effectively reduce HIV RNA to $<1,000$ copies/ $\mathrm{ml}$ or undetectable levels have very low rates of PT (Cooper et al. 2002). However, because transmission can occur even at low or undetectable HIV RNA copy numbers, HIV RNA levels should not be a determining factor when deciding whether to use ARV drugs for prevention of PT. Additionally, the efficacy of ARV drugs is not solely related to lowering viral load (Cooper et al. 2002; Ioannidis et al. 2001). Therefore, ARV prophylaxis should be given even to women who have a very low or undetectable viral load on no therapy.

\section{Intrapartum ARV therapy/prophylaxis}

\subsection{Women who have received antepartum ARV drugs}

The PACTG 076 results and subsequent epidemiologic studies have proven the efficacy of the three-part zidovudine chemoprophylaxis regimen alone or in combination with other ARV agents. The PACTG 076 zidovudine regimen includes a continuous intravenous infusion of zidovudine during labor (initial loading dose of $2 \mathrm{mg} / \mathrm{kg}$ intravenously over 1 hour, followed by continuous infusion of $1 \mathrm{mg} / \mathrm{kg} /$ hour until delivery). Therefore, intravenous zidovudine during the intrapartum period should be discussed with and recommended to all HIV-infected pregnant women. For a scheduled cesarean delivery, intravenous zidovudine should begin 3 hours before surgery, according to standard dosing recommendations. Women receiving fixed-dose combination regimens that include zidovudine (e.g., the zidovudine/lamivudine combination) should have zidovudine administered intravenously during labor while other ARV components are continued orally (e.g., if a woman is receiving zidovudine/lamivudine during pregnancy, zidovudine should be given intravenously and lamivudine should be given orally during labor).

If known or suspected zidovudine resistance or toxicity has precluded antenatal use of zidovudine, intrapartum zidovudine according to the PACTG 076 protocol should still be recommended unless a woman has a documented history of hypersensitivity. This intrapartum use of the drug is recommended due to the unique characteristics of zidovudine and its proven record in reducing PT.

There is a pharmacologic antagonism between zidovudine and stavudine, and therefore these drugs should not be co-administered during labor. Women who are receiving an antepartum stavudine-containing regimen should discontinue stavudine during labor while intravenous zidovudine is being administered, with other components of the regimen continued orally.

\subsection{Women who have received antepartum ARV drugs but have suboptimal viral suppression near delivery}

Women who have received ART may not achieve complete viral suppression by the time of delivery due to factors such as poor adherence, viral resistance, or late entry into care. Regardless of the reason, all women who have HIV RNA levels $>1,000$ copies/ml near the time of delivery should be offered a scheduled cesarean delivery at 38 weeks, which may significantly reduce the risk of transmission.

The addition of single-dose nevirapine during labor has not been shown to reduce PT of HIV in this group of women. The PACTG 316 study, conducted in women in the United States, Europe, Brazil, and the Bahamas who were receiving ARV drugs during pregnancy (primarily combination therapy), showed that the addition of single-dose nevirapine did not reduce the risk of MTCT of HIV even in the setting of maternal viremia but was associated 
with the development of nevirapine resistance in $15 \%$ of women with detectable HIV RNA postpartum (Cunningham et al. 2002). However, the number of women with detectable HIV RNA at delivery, and especially with HIV RNA $>10,000$ copies/ml, was small and may have been insufficient to allow assessment of a possible benefit of single-dose nevirapine in this subgroup. Given the risk of development of resistance and the lack of data to suggest added efficacy, addition of single-dose nevirapine when a woman has received antepartum drugs is generally not recommended.

\subsection{Women who have not received antepartum ARV drugs}

All HIV-infected women who have not received antepartum ART should have intravenous zidovudine started immediately to prevent PT of HIV. Although intrapartum/neonatal ARTs will not prevent PT that occurs before labor, most transmission occurs near to or during labor and delivery. Pre-exposure prophylaxis for the fetus can be provided by giving the mother a drug that rapidly crosses the placenta to produce systemic ARV drug levels in the fetus during intensive exposure to HIV in maternal genital secretions and blood during birth. In general, zidovudine and other NRTI drugs as well as NNRTI drugs cross the placenta well, although protease inhibitors drugs do not.

Epidemiologic data indicate that intravenous maternal intrapartum zidovudine followed by oral zidovudine for 6 weeks for the infant significantly reduces transmission compared to no treatment (Wade et al. 1998). In a New York State cohort study, transmission rates were $10 \%$ with intrapartum and neonatal zidovudine compared with $27 \%$ without zidovudine, a $62 \%$ reduction in risk (Wade et al. 1998). The PETRA study demonstrated that intrapartum prophylaxis alone, without an infant post-exposure prophylaxis component, is not effective in reducing PT (Petra Study Team, 2002).

Whether the addition of other ARV drugs to the intravenous intrapartum/newborn zidovudine regimen when no maternal antepartum drugs have been received increases efficacy in preventing PT has not been directly studied. Several intrapartum/neonatal prophylaxis regimens have been found to be effective in international studies. These include oral zidovudine/lamivudine during labor followed by one week of oral zidovudine/lamivudine to the infant and single-dose intrapartum/newborn nevirapine (Petra Study Team, 2002). However, none of these regimens has been compared to intravenous zidovudine combined with 6 weeks of infant zidovudine prophylaxis.

Studies need to address whether adding drugs to the intravenous intrapartum/newborn zidovudine regimen will enhance efficacy in reducing PT. In the absence of data, some experts feel additional drugs may be warranted. One option is to add the single-dose intrapartum/newborn nevirapine regimen to the intravenous/6-week infant zidovudine regimen. Although single-dose nevirapine did not provide additional efficacy when added to antepartum combination ARV regimens in PACTG 316, in this situation, no maternal antepartum therapy has been given. Theoretical advantages of combining the zidovudine and nevirapine intrapartum/neonatal regimens include the known short-term safety of each regimen alone, excellent tranplacental passage of both drugs, greater antiviral activity of nevirapine compared to zidovudine, as well as the activity of nevirapine against extracellular and intracellular virus (Musoke et al. 1999) and the known synergy of zidovudine and nevirapine in inhibiting HIV replication in vitro (Koup et al. 1993). However, single-dose nevirapine is associated with the development of nevirapine -resistant virus (Jourdain et al. 2004). 
Studies have shown that nevirapine resistance after intrapartum administration of singledose nevirapine can be substantially reduced (but not eliminated) by using a short postpartum course of ARV agents from alternate classes (a "tail"). There is no current consensus about the exact duration or composition of the ARV tail. Several trials in Africa have found 3 to 7 days of maternal/infant postpartum zidovudine/lamivudine to be effective (Chaix et al. 2006; McIntyre et al. 2009). Development of resistance to zidovudine or lamivudine given for a short period in this setting is rare (Mandelbrot et al. 2001).

More recent studies have found that 7 days of tenofovir/emtricitabine (TEmAA ANRS 12109 Study Group, 2009), 7 days of zidovudine/didanosine/lopinavir-ritonavir (Van Dyke et al. 2009), and 30 days of zidovudine/didanosine or zidovudine/didanosine/lopinavirritonavir (Lallemant et al. 2010) all appear to be effective at reducing the development of nevirapine resistance.

\section{The efficiency of current anti-HIV treatments}

The efficacy of ARV drugs in preventing MTCT of HIV varies with the type of regimen used and the duration over which it is given. Combination regimens which include different types of ARV drugs are more efficacious than monotherapies as discussed above. It is well known that monotherapies can lead to ARV resistance in the virus, which may limit future therapeutic options when treatment is needed. According to the 2010 WHO treatment guidelines it is recommended that pregnant women living with HIV and their exposed infants receive combination therapy rather than single-dose nevirapine. ARV prophylaxis is also recommended during breastfeeding in settings where breastfeeding is judged to be the safest infant feeding option. In addition, all women eligible for treatment under WHO guidelines should receive an appropriate combination therapy for their own health $\mathrm{WHO}$, 2010).

\section{Practice and procedures}

Three types of interventions should be tackled by any program concerned with prevention of mother-to-child transmission of HIV: primary prevention of HIV-1 in women; prophylaxis with ARV drugs in breastfeeding infants and prophylaxis with ARV drugs for lactating mothers. Administration of zidovudine to the pregnant woman and her infant could reduce the risk of perinatal transmission by nearly $70 \%$. Combination ARV prophylaxis given to the mother antenatally is associated with further declines in transmission to $<2 \%$. Combination regimens are more effective than single-drug regimens in reducing perinatal transmission.

\section{Chapter key facts}

- Zidovudine administration to the pregnant woman and her infant can reduce the risk of perinatal transmission by nearly $70 \%$.

- Combination regimens are more effective than single-drug regimens in reducing perinatal transmission. A longer three-part regimen given antenatally, intrapartum, and postpartum is superior in preventing perinatal transmission than a shorter two-part antepartum/intrapartum or intrapartum/postpartum regimen.

- The standard recommendation for infant prophylaxis in the absence of maternal antenatal and intrapartum therapy is six weeks of infant zidovudine. The addition of 
single-dose intrapartum nevirapine is generally not recommended for women who are receiving the standard recommended antenatal antiretroviral prophylaxis regimens.

- Antiretroviral prophylaxis should be given to women who have a very low or undetectable viral load on no therapy.

- Intravenous zidovudine during the intrapartum period should be discussed with and recommended to all HIV-infected pregnant women.

\section{Summary points of chapter}

- $\quad$ HIV is the leading cause of death in women of reproductive age.

- HIV testing and counseling should be undertaken and should be entirely voluntary.

- Three types of interventions should be tackled by any program concerned with prevention of mother-to-child transmission: primary prevention of HIV in women; prophylaxis with antiretroviral drugs in breastfeeding infants and prophylaxis with antiretroviral drugs for lactating mothers.

- Taking antiretroviral treatment can reduce the risk of mother-to-child transmission.

- Administration of zidovudine to the pregnant woman and her infant could significantly reduce the risk of perinatal transmission.

- Combination antiretroviral prophylaxis (initially dual and then triple combination therapy) given to the mother antenatally can further declines the transmission significantly.

- Regardless of the reason, all women who have HIV RNA levels $>1,000$ copies/ml near the time of delivery should be offered a scheduled cesarean delivery at 38 weeks, which may significantly reduce the risk of transmission.

- Given the risk of development of resistance, addition of single-dose nevirapine when a woman has received antepartum drugs is generally not recommended.

\section{Definitions and explanations of words and terms}

Antenatal
Antepartum
Antiretroviral
Antiretroviral Therapy
Intrapartum
Intravenous

Labour

Microbicides

Monotherapy

Mother to child transmission

Perinatal
Before birth

Before labour or child birth

Drugs used for the treatment of antiretroviral infections

Drugs used against retroviruses such as HIV

During labour and delivery or childbirth

Occurring or introduced to within a vein or veins usually by means of injection

The process of child birth

An agent destructive to microbes

Single drug treatment

Is the transfer of an agent (e.g. HIV) from the mother to her unborn or born baby

Occurring during, or pertaining to, the periods before, during, or after the time of birth i.e. before delivery from 
Pharmacologic Antagonism

Prophylaxis

Viral Resistance the $28^{\text {th }}$ week of gestation through the first 7 days after delivery

Opposition in action of drugs

Protection treatment against disease

The development of mutation within the virus genome that leads to the virus becoming resistance to the drug treatment

\section{List of abbreviations}

$\begin{array}{ll}\text { ART } & \text { Antiretroviral Therapy } \\ \text { ARV } & \text { Antiretroviral } \\ \text { PT } & \text { Perinatal Transmission } \\ \text { RNA } & \text { Ribonucleic acid } \\ \text { UNAIDS } & \text { United Nations AIDS } \\ \text { NRTI } & \text { Nucleoside reverse transcriptase inhibitors } \\ \text { NNRTI } & \text { Non-nucleoside reverse transcriptase inhibitors }\end{array}$

\section{References}

Al-Jabri, A.A. and F.Q. Alenzi. 2009. Vaccines, virucides and drugs against HIV/AIDS: Hopes and optimisms for the future. The Open AIDS Journal 3: 1-3.

Al-Jabri A.A. Al-Muharrmi Z.K., Balkhair A.A. and Ganguly S. 2010. The importance of antenatal screening of HIV among pregnant women. Saudi Medical Journal 31:64-8.

Bolu, O.O. and V. Allread, T. Creek, E. Stringer, F. Forna, M. Bulterys and N. Shaffer. 2007. Approaches for scaling up human immunodeficiency virus testing and counseling in prevention of mother-to-child human immunodeficiency virus transmission settings in resource-limited countries. Am J Obstet Gynecol. 197:S83-9.

CDC. 2006. Achievements in public health. Reduction in perinatal transmission of HIV infection--United States, 1985-2005. MMWR Morb Mortal Wkly Rep. 55:592-597.

Chaix, M.L. and D.K. Ekouevi, F. Rouet, B. Tonwe-Gold, I. Viho, L. Bequet, G. Peytavin, H. Toure, H. Menan, V. Leroy, F. Dabis, C. Rouzioux; Agence Nationale de Recherches sur le SIDA Ditrame Plus Study Group. 2006. Low risk of nevirapine resistance mutations in the prevention of mother-to-child transmission of HIV-1: Agence Nationale de Recherches sur le SIDA Ditrame Plus, Abidjan, Cote d'Ivoire. J. Infect. Dis. 193:482-487.

Cooper, E.R. and M. Charurat, L. Mofenson, C. Hanson, J. Pitt, C. Diaz, K. Hayani, E. Handelsman, V. Smeruglio, R. Hoff and W. Blattner. 2002. Combination antiretroviral strategies for the treatment of pregnant HIV-1-infected women and prevention of perinatal HIV-1-transmission. JAIDS. 29:484-494.

Connor, E.M. and R.S. Sperling, R. Gelber, P. Kiselev, G. Scott, M.J. O'Sullivan, R. Van Dyke, M. Bey, W. Shearer, R.L. Jacobson, E. Jimenez, E.O'Neill, B. Bazin, J-F. Delfraissy, M. Culnane, R. Coombs, M. Elkins, J. Moye, P. Stratton and J. Balsley. 1994. Reduction of maternal-infant transmission of human immunodeficiency virus type 1 with Zidovudine treatment. N. Engl. J. Med. 331:1173-1180. 
Cunningham, C.K. and M.L. Chaix, C. Rekacewicz, P. Britto, C. Rouzioux, R.D. Gelber, A. Dorenbaum, J.F. Delfraissy, B. Bazin, L. Mofenson and J.L. Sullivan. 2002. Development of resistance mutations in women receiving standard antiretroviral therapy who received intrapartum nevirapine to prevent perinatal human immunodeficiency virus type 1 transmission: a substudy of pediatric AIDS clinical trials group protocol 316. J. Infect. Dis. 186:181-188.

Hart, C.E. and J.L. Lennox, M. Pratt-Palmore, T.C. Wright, R.F. Schinazi, T. EvansStrickfaden, T.J. Bush, C. Schnell, L.J. Conley, K.A. Clancy and T.V. Ellerbrock. 1999. Correlation of human immunodeficiency virus type 1 RNA levels in blood and the female genital tract. J. Infect. Dis. 179:871-882.

Ioannidis, J.P. and E.J. Abrams, A. Ammann, M. Bulterys, J.J. Goedert, L. Gray, B.T. Korber, M.J. Mayaux, L.M. Mofenson, M.L. Newell, D.E. Shapiro, J.P. Teglas and C.M. Wilfert. 2001. Perinatal transmission of human immunodeficiency virus type 1 by pregnant women with RNA virus loads $<1000$ copies/ml. J. Infect. Dis. 183:539-545.

Jourdain, G. and N. Ngo-Giang-Huong S. Le Coeur, C. Bowonwatanuwong, P. Kantipong, P. Leechanachai, S. Ariyadej, P. Leenasirimakul, S. Hammer, M. Lallemant; Perinatal HIV Prevention Trial Group. 2004. Intrapartum exposure to nevirapine and subsequent maternal responses to nevirapine-based antiretroviral therapy. N. Engl. J. Med. 351:229-240.

Koup, R.A and F. Brewster, P. Grob and J.L. Sullivan. 1993. Nevirapine synergistically inhibits HIV-1 replication in combination with zidovudine, interferon or CD4 immunoadhesin. AIDS. 7:1181-1184.

Lallemant, M. and N. Ngo-Giang-Huong G. Jourdain, P. Traisaithit, T.R. Cressey, I.J. Collins, T. Jarupanich, T. Sukhumanant, J. Achalapong, P. Sabsanong, N. Chotivanich, N. Winiyakul, S. Ariyadej, A. Kanjanasing, J. Ratanakosol, J. Hemvuttiphan, K. Kengsakul, W. Wannapira, V. Sittipiyasakul, W. Pornkitprasarn, P. Liampongsabuddhi, K. McIntosh, R.B. Van Dyke, L.M. Frenkel, S. Koetsawang, S. Le Coeur, S. Kanchana; PHPT-4 Study Team. 2010. Efficacy and safety of 1-month postpartum zidovudine-didanosine to prevent HIV-resistance mutations after intrapartum single-dose nevirapine. Clin. Infect. Dis. 50:898-908.

Mandelbrot, L. and A. Landreau-Mascaro, C. Rekacewicz, A. Berrebi, J.L. Bénifla, M. Burgard, E. Lachassine, B. Barret, M.L. Chaix, A. Bongain, N. Ciraru-Vigneron, C. Crenn-Hébert, J.F. Delfraissy, C. Rouzioux, M.J. Mayaux, S. Blanche; Agence Nationale de Recherches sur le SIDA (ANRS) 075 Study Group. 2001. Lamivudinezidovudine combination for prevention of maternal-infant transmission of HIV-1. JAMA. 285:2083-2093.

McIntyre, J.A. and M. Hopley, D. Moodley, M. Eklund, G.E. Gray, D.B. Hall, P. Robinson, D. Mayers and N.A. Martinson. 2009. Efficacy of short-course AZT plus 3TC to reduce nevirapine resistance in the prevention of mother-to-child HIV transmission: a randomized clinical trial. PLoS Med. 6:e1000172.

Mock, P.A. and N. Shaffer, C. Bhadrakom, W. Siriwasin, T. Chotpitayasunondh, S. Chearskul, N.L. Young, A. Roongpisuthipong, P. Chinayon, M.L. Kalish, B. Parekh and T.D. Mastro. 1999. Maternal viral load and timing of mother-to-child HIV transmission, Bangkok, Thailand. Bangkok Collaborative Perinatal HIV Transmission Study Group. AIDS. 13:407-414. 
Musoke, P. and L. Guay, D. Bagenda, M. Mirochnick, C. Nakabiito, T. Fleming, T. Elliott, S. Horton, K. Dransfield, J.W. Pav, A. Murarka, M. Allen, M.G. Fowler, L. Mofenson, D. Hom, F. Mmiro and J.B. Jackson. 1999. A phase I/II study of the safety and pharmacokinetics of nevirapine in HIV-1-infected pregnant Ugandan women and their neonates (HIVNET 006). AIDS. 13:479-486.

Petra Study Team. 2002. Efficacy of three short-course regimens of zidovudine and lamivudine in preventing early and late transmission of HIV-1 from mother to child in Tanzania, South Africa, and Uganda (Petra study): a randomised, doubleblind, placebo-controlled trial. Lancet 359:1178-1186.

Shapiro, D.E. and R.S. Sperling and R.W. Coombs. 1999. Effect of zidovudine on perinatal HIV-1 transmission and maternal viral load. Lancet 354:156; author reply 157-158.

Sperling R.S. and D.E. Shapiro, R.W. Coombs, J.A. Todd, S.A. Herman, G.D. McSherry, M.J. O'Sullivan, R.B. Van Dyke, E. Jimenez, C. Rouzioux, P.M. Flynn and J.L. Sullivan. 1996. Maternal viral load, zidovudine treatment, and the risk of transmission of human immunodeficiency virus type 1 from mother to infant. Pediatric AIDS Clinical Trials Group Protocol 076 Study Group. N Engl J Med. 335:1621-1629.

TEmAA ANRS 12109 Study Group. 2009. Tolerance and viral resistance after single-dose nevirapine with tenofovir and emtricitabine to prevent vertical transmission of HIV-1. AIDS 23:825-833.

The European Collaborative Study. 1999. Maternal viral load and vertical transmission of HIV-1: an important factor but not the only one. AIDS 13:1377-1385.

Van Dyke, R. and G. Jourdain and D. Shapiro. 2009. A Phase II Study of the incidence of nevirapine resistance mutations in HIV-infected Thai women receiving a single intrapartum dose of NVP followed by a postpartum tail of ZDV/ddI or ZDV/ddI/LPV/r: IMPAACT P1032. Paper presented at: 16th Conference on Retroviruses and Opportunistic Infections; February 8-11, 2009; Montreal, Canada. Abstract 95aLB.

Wade, N.A. and G.S. Birkhead, B.L. Warren, T.T. Charbonneau, P.T. French, L. Wang, J.B. Baum, J.M. Tesoriero and R. Savicki. 1998. Abbreviated regimens of zidovudine prophylaxis and perinatal transmission of the human immunodeficiency virus. $\mathrm{N}$. Engl. J. Med. 339:1409-1414.

WHO \& UNAIDS. 2010. Global Report, UNAIDS report on the global AIDS epidemic. WHO \& UNAIDS. 1999. HIV in pregnancy. WHO/CHS/RHR/99.15, UNAIDS/99.35E.

WHO. 2010. Antiretroviral drugs for treating pregnant women and preventing HIV infection in infants: towards universal access 2010

http://www.who.int/hiv/pub/mtct/antiretroviral2010/en/index.html 


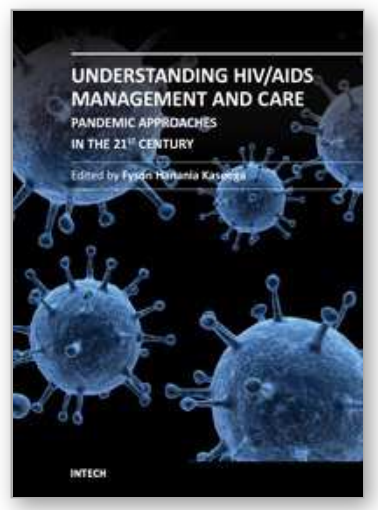

\author{
Understanding HIV/AIDS Management and Care - Pandemic \\ Approaches in the 21st Century \\ Edited by Dr. Fyson Kasenga
}

ISBN 978-953-307-603-4

Hard cover, 384 pages

Publisher InTech

Published online 14, December, 2011

Published in print edition December, 2011

Like any other book on the subject of HIV/AIDS, this book is not a substitute or exhausting the subject in question. It aims at complementing what is already in circulation and adds value to clarification of certain concepts to create more room for reasoning and being part of the solution to this global pandemic. It is further expected to complement a wide range of studies done on this subject, and provide a platform for the more updated information on this subject. It is the hope of the authors that the book will provide the readers with more knowledge and skills to do more to reduce HIV transmission and improve the quality of life of those that are infected or affected by HIV/AIDS.

\title{
How to reference
}

In order to correctly reference this scholarly work, feel free to copy and paste the following:

Ali A. Al-Jabri, Abdullah A. Balkhair, Mohammed S. Al-Balosh and Sidgi S. Hasson (2011). Antenatal Screening and HIV-Pregnancy: Strategies for Treatment, Understanding HIV/AIDS Management and Care - Pandemic Approaches in the 21st Century, Dr. Fyson Kasenga (Ed.), ISBN: 978-953-307-603-4, InTech, Available from: http://www.intechopen.com/books/understanding-hiv-aids-management-and-care-pandemic-approaches-inthe-21st-century/antenatal-screening-and-hiv-pregnancy-strategies-for-treatment

\section{INTECH}

open science | open minds

\section{InTech Europe}

University Campus STeP Ri

Slavka Krautzeka 83/A

51000 Rijeka, Croatia

Phone: +385 (51) 770447

Fax: +385 (51) 686166

www.intechopen.com

\section{InTech China}

Unit 405, Office Block, Hotel Equatorial Shanghai

No.65, Yan An Road (West), Shanghai, 200040, China 中国上海市延安西路65号上海国际贵都大饭店办公楼405单元

Phone: +86-21-62489820

Fax: +86-21-62489821 
(C) 2011 The Author(s). Licensee IntechOpen. This is an open access article distributed under the terms of the Creative Commons Attribution 3.0 License, which permits unrestricted use, distribution, and reproduction in any medium, provided the original work is properly cited. 